\title{
Microquimerismo Fetal-Materno nas Doenças Reumáticas Auto-Imunes ${ }^{(*)}$
}

\section{Maternal-Fetal Microchimerism in Autoimmune Rheumatic Diseases}

\author{
Karin Spat Albino Barcellos ${ }^{(1)}$ e Luís Eduardo Coelho Andrade ${ }^{(2)}$
}

\section{RESUMO}

Estudos recentes indicam a existência de um tráfego bidirecional de células durante a gestação humana normal. Células fetais persistem no sangue periférico materno por muitos anos após a gestação. Muitas doenças auto-imunes são mais prevalentes em mulheres, algumas das quais apresentam pico de incidência em fases tardias dos anos férteis femininos. A doença enxerto-versushospedeiro é uma condição conhecida de quimerismo e possui similaridades clínicas com algumas doenças auto-imunes reumáticas, notavelmente com esclerose sistêmica e síndrome de Sjögren e, algumas vezes, com lúpus eritematoso sistêmico. Este artigo explora a hipótese de que o microquimerismo fetal contribua para a patogênese de algumas doenças auto-imunes, baseado em revisões de estudos anteriores que trabalharam com esta hipótese. São apresentadas ressalvas de ordem conceitual e técnica a serem consideradas na interpretação dos dados da literatura.

Palavras-chave: microquimerismo, doença reumática autoimune, auto-imunidade, esclerose sistêmica, lúpus eritematoso sistêmico.

\section{INTRODUÇÃO}

$\mathrm{Na}$ mitologia, o termo quimera descrevia uma criatura com cabeça de leão, corpo de capricórnio e cauda de serpente. Na medicina, o termo quimerismo é utilizado quando um indivíduo contém populações de células derivadas de diferentes indivíduos (células não próprias); quando há baixos níveis destas células, utiliza-se o termo microquimerismo. Está bem documentada a existência de um tráfego bidirecional entre a mãe e o feto durante a gestação, sendo

\begin{abstract}
Recent studies indicate that there is bi-directional traffic of cells during normal human pregnancy. Fetal cells have been found to persist in the maternal peripheral blood for many years after pregnancy. Many autoimmune diseases are more prevalent in women, and some of them have peak incidence at late stages of childbearing years. Chronic graft versus host disease (cGVHD) is a known condition of chimerism and has clinical similarities to some rheumatic autoimmune diseases, notably systemic sclerosis, Sjögren's syndrome and systemic lupus erythematosus. This article explores the hypothesis that fetal microchimerism contributes to the pathogenesis of some autoimmune diseases, based on reviews of previous studies that have worked with this hypothesis. Technical and conceptual considerations are presented for a critical appraisal of the available literature.
\end{abstract}

Keywords: microchimerism, rheumatic autoimmune disease, autoimmunity, systemic sclerosis, systemic lupus erythematosus.

que as células fetais passam, rotineiramente, para a circulação materna durante o curso de uma gravidez normal. Células fetais são normalmente encontradas no sangue periférico materno no primeiro trimestre da gravidez, sendo detectadas já a partir de cinco semanas de gestação ${ }^{(1,2)}$. A carga de DNA fetal aumenta progressivamente ao longo da gravidez, com um incremento ainda maior na época do parto $^{(3)}$. Em 1996, Bianchi et a $l^{(4)}$ demonstraram que células fetais podem ser detectadas no sangue periférico materno até 27 anos após o parto. Para este estudo os autores

\footnotetext{
* Disciplina de Reumatologia, Escola Paulista de Medicina, Universidade Federal de São Paulo. (EMP-UNIFESP). Trabalho recebido em 13/10/03. Aprovado, após revisão, em 19/01/04. Trabalho realizado com apoio do Conselho Nacional de Desenvolvimento e Pesquisa (CNPq) e do Fundo de Auxílio e Pesquisa em Ensino em Reumatologia da Sociedade Brasileira de Reumatologia.

1. Pós-Graduanda. EPM-UNIFESP.

2. Professor Adjunto. EPM-UNIFESP.

Endereço para correspondência: Luís Eduardo Coelho Andrade. Disciplina de Reumatologia. Rua Botucatu, 740, CEP 04023-900, Vila Clementino, São Paulo, SP. E-mail:luis@reumato.epm.br
} 
selecionaram mulheres com filhos do sexo masculino, motivados pela facilidade com que pequenas quantidades de DNA masculino podem ser detectadas no organismo feminino. Seis de oito mulheres sadias apresentaram DNA masculino na população de células progenitoras circulantes (células CD34+ e CD38+), células estas que derivam de uma célula-tronco e que podem se diferenciar em outras células imunocompetentes (incluindo os linfócitos). Uma mulher do estudo também apresentou DNA masculino na população de linfócito $\mathrm{T}$ (células CD3+). Desta forma, foi demonstrada a persistência prolongada de células progenitoras fetais na circulação materna após a gestação.

As doenças auto-imunes em geral apresentam predileção por mulheres e algumas dessas doenças possuem pico de incidência na mulher madura ou mesmo após os anos férteis femininos. Já foi demonstrado que os hormônios sexuais apresentam efeitos na função imunológica e na autoimunidade ${ }^{(5)}$; entretanto, apenas as diferenças nos hormônios sexuais entre homens e mulheres parecem não ser suficientes para explicar a predominância feminina em doenças autoimunes. Gravidez é um evento unicamente feminino com drásticas mudanças hormonais; a exposição a células fetais representa um evento imunológico, uma vez que essas células expressam produtos genéticos que são herdados do pai, sendo, então, estranhos para a mulher grávida ${ }^{(6)}$.

A doença enxerto-versus-hospedeiro (GVHD) crônica, após transplante de células tronco, é uma condição de quimerismo e apresenta similaridades com algumas doenças auto-imunes. Alguns pacientes com GVHD crônica apresentam manifestações clínicas similares às manifestações encontradas na esclerose sistêmica (ES), na cirrose biliar primária, na síndrome de Sjögren (SSj), no lúpus eritematoso sistêmico (LES) e nas miopatias inflamatórias idiopáticas $^{(7)}$. Como as células fetais podem persistir na circulação materna por décadas após o término da gestação e as doenças reumáticas auto-imunes apresentam maior incidência em mulheres, bem como manifestações clínicas similares às da GVHD crônica, foi sugerida a hipótese de que o microquimerismo fetal esteja envolvido na patogênese de algumas doenças reumáticas auto-imunes.

Há outras possíveis origens para o microquimerismo em mulheres nuligestas e em homens, tais como o enxertamento de células através de uma transfusão sanguínea ${ }^{(8)} \mathrm{ou}$ enxertamento através de gêmeos ${ }^{(9)}$. Como as células maternas também passam para a circulação fetal, outra origem para o quimerismo pode ser materna; foi descrito que células maternas são, normalmente, encontradas em amostras de cordão umbilical ${ }^{(10,11)}$.
A seguir serão comentadas as evidências sugestivas de presença de microquimerismo fetal em algumas doenças reumáticas auto-imunes.

\section{MICROQUIMERISMO NA ESCLEROSE SISTÊMICA}

A ES apresenta maior incidência em mulheres, com maior incidência na meia idade. Certas características da ES são compartilhadas por pacientes com GVHD crônica. Ambos os tipos de pacientes apresentam endurecimento progressivo da pele, resultando em considerável disfunção da mesma e contraturas nas juntas. Ademais, ambas as doenças normalmente envolvem o intestino e os pulmões ${ }^{(12)}$. Muitos pacientes com GVHD crônica possuem teste positivo para anticorpos antinúcleo ${ }^{(13,14)}$. Dessa forma, houve um grande interesse em testar a hipótese do microquimerismo celular fetal estar envolvido na patogênese da ES. Um estudo conduzido por Nelson et al. em mulheres com ES e controles saudáveis (todas com pelo menos um filho do sexo masculino) foi realizado através de Reação em Cadeia da Polimerase (PCR) quantitativa para testar a presença de uma seqüência específica do cromossomo $\mathrm{Y}$ em sangue periférico ${ }^{(15)}$. Os resultados foram expressos como o número de cópias desta seqüência de DNA em amostra de $16 \mathrm{ml}$ de sangue total. A média de células masculinas nas mulheres com ES (11,1, variando de 0 a 61) foi significantemente maior do que nos controles (0,38, variando de 0 a 2$)$. Em algumas pacientes, mesmo com filhos nascidos havia muitos anos, a carga de DNA masculino era maior do que a encontrada na maioria das mulheres hígidas grávidas de fetos normais masculinos ${ }^{(15)}$. Em 1998, Artlett et al. ${ }^{(16)}$ investigaram espécimes de biópsias de pele, um tecido alvo preferencial em pacientes com ES. O estudo foi realizado utilizando nested PCR para identificar seqüências do cromossomo Y em DNA extraído de células do sangue periférico e de lesões da pele de mulheres com ES. Seqüências do cromossomo $\mathrm{Y}$ foram encontradas no sangue periférico em 32 das 69 mulheres esclerodérmicas (46\%) e em apenas 1 das 25 mulheres normais (4\%). Seqüências do cromossomo $\mathrm{Y}$ foram encontradas nas biópsias de pele em 11 das 19 pacientes (58\%), entretanto não foram encontradas nas biópsias de pele dos controles. Ademais, em cada paciente esclerodérmica o teor de seqüência de DNA masculino foi estatisticamente superior entre células da pele em comparação às células do sangue periférico. Estes resultados sustentam a hipótese de uma participação do microquimerismo fetal na patogênese da ES.

Recentemente, foi realizado um trabalho com o objetivo de identificar e quantificar uma possível especificidade 
tecidual do microquimerismo fetal em mulheres com $\mathrm{ES}^{(17)}$. Múltiplos espécimes de tecidos obtidos em autópsia de mulheres com ES que tiveram filhos homens, assim como de mulheres que haviam morrido de causas não relacionadas à auto-imunidade, foram analisados através de hibridização in situ fluorescente para a detecção de células masculinas. Os tecidos estudados eram provenientes de glândula adrenal, coração, intestino, rins, figado, pulmão, linfonodos, pâncreas, paratireóide, pele e baço. Nas mulheres com ES, células masculinas foram identificadas em pelo menos um dos tipos de tecido, sendo encontradas com maior freqüência no baço. Estas células não foram encontradas nos espécimes teciduais das mulheres que haviam morrido de causas não relacionadas à auto-imunidade. Esses resultados sugerem que as células fetais migram da circulação periférica para os múltiplos órgãos em mulheres com ES. A presença das células fetais em órgãos internos sugere uma possível participação das mesmas na etiopatogenia da doença. Alternativamente, esta presença pode representar uma conseqüência da doença em razão da migração de células progenitoras preferencialmente para as áreas de tecido danificado.

Nos últimos anos, alguns dos mecanismos patogênicos responsáveis pelas alterações vistas nos pacientes com ES têm sido parcialmente esclarecidos. Um número aumentado de células T CD4+ foi encontrado em lesões da pele e em outros órgãos de pacientes com ES nos primeiros estágios da doença ${ }^{(18,19)}$. Citocinas capazes de alterar as funções das células endoteliais ou de induzir fibrose foram detectadas no soro e nos tecidos de esclerodérmicos, sugerindo, assim, que citocinas secretadas pelas células $T$ ou por outras células do sistema imunológico talvez tenham uma importante participação na patogênese da doença ${ }^{(18,19)}$. As células $T$ CD4+ apresentam duas subpopulações conhecidas como tipo 1 (Th1) e tipo 2 (Th2), distintas pelo perfil de citocinas produzidas. As células Th1 produzem IL-2, IFN $\gamma$ e TNF $\beta$, e dessa maneira são responsáveis pela resposta imunológica dependente de fagócito, envolvida na proteção contra parasitas intracelulares. As células Th2 produzem IL-4, IL5 e IL-13, sendo, então, responsáveis pela resposta mediada por anticorpos e resposta independente de fagócito ${ }^{(20,21)}$. Foi descrita a existência de ativação predominante de células Th2 produtoras de IL-4 em pacientes com esclerose sistêmica, o que poderia estar associado às principais alterações presentes na doença ${ }^{(22-25)}$. A origem dessa resposta imune mediada principalmente por células Th2 nesses pacientes ainda não está clara, mas é intrigante que na GVHD também predomine uma resposta mediada por células $\operatorname{Th} 2^{(26,27)}$.
Alguns estudos descritos anteriormente nesta revisão sugeriram que um microquimerismo estabelecido pelas células $\mathrm{T}$ fetais e uma subseqüente ativação dessas células poderiam induzir uma reação enxerto-versus-hospedeiro manifesta na forma de esclerose sistêmica ${ }^{(15,16)}$. Em 2002, Scaletti et al. ${ }^{(28)}$ realizaram um estudo com o objetivo de caracterizar o perfil de citocinas das células $\mathrm{T}$ presentes no sangue e na pele de mulheres com ES e fetais reativas contra os antígenos MHC maternos. Para isso, clones de célula T foram gerados a partir de sangue periférico e de biópsia de pele de 3 pacientes no início da doença. Também foram gerados clones a partir de sangue periférico de 3 mulheres sadias (todas as 6 mulheres possuíam pelo menos um filho do sexo masculino). Os clones de célula $\mathrm{T}$ materna eram analisados pela sua capacidade de proliferar in vitro em resposta a antígenos MHC maternos. Os clones proliferados eram examinados quanto à presença de seqüências específicas do cromossomo Y. As concentrações de IFN $\gamma$ e TNF $\beta$ liberados pelos clones de célula $T$ em resposta aos antígenos MHC maternos também foram avaliadas. Dos clones de célula $\mathrm{T}$ materna que proliferaram em resposta a antígenos MHC maternos, sete obtidos de pacientes com ES e um de mulher sadia apresentaram seqüência específica do cromossomo $\mathrm{Y}$, demonstrando que eles derivavam de células $\mathrm{T}$ fetais. Todos os clones gerados de células $\mathrm{T}$ masculinas provenientes de mulheres com ES produziram níveis de IL-4 significantemente maiores em resposta à estimulação com antígenos MHC maternos com relação aos outros clones gerados das mesmas mulheres (clones estes que responderam a mesma estimulação, mas não apresentaram seqüências do cromossomo Y); esta diferença nos níveis de IL-4 não ocorreu entre os clones de mulheres sadias. Este estudo demonstrou que as células T fetais presentes no sangue e/ou na pele de mulheres com ES e que reagem com os antígenos MHC maternos exibem um perfil Th2 orientado, sustentando uma participação destas células na GVHD e possivelmente na ES nas mulheres.

\section{GENES HLA DE MÃES E fILHOS NA ESCLEROSE SISTÊMICA}

Moléculas HLA são determinantes críticos de respostas imunes e moléculas HLA de classe II específicas foram descritas em associação com uma variedade de doenças auto-imunes. Foi proposto que após o nascimento de uma criança com HLA compatível com o da mãe o risco de uma futura doença auto-imune na mãe poderia aumentar ${ }^{(29)}$. A compatibilidade do HLA foi estudada sob a perspectiva do paciente: uma criança é compatível quando possui HLA idêntico ao 
materno ou os genes HLA em homozigose. Nelson et al. demonstraram que mulheres com ES haviam dado à luz crianças com HLA classe II compatível ao materno com maior freqüência do que as mulheres do grupo controle, sendo o aumento desta freqüência maior para os alelos HLA-DRB1. A diferença entre os pacientes e os controles estava aumentada quando a criança era homozigota (compatível em razão da homozigose do HLA-DRB1) ${ }^{(15)}$. Nenhuma associação semelhante foi encontrada para os antígenos HLA de classe I. O efeito da homozigose apresenta um interesse adicional, uma vez que GVHD foi descrita em receptores imunocompetentes de transfusão sangüínea de doadores aparentados compatíveis por homozigose dos antígenos HLA ${ }^{(30)}$.

\section{MICROQUIMERISMO FETAL NO LÚPUS ERITEMATOSO SISTÊMICO}

O lúpus eritematoso sistêmico é uma doença de interesse para a investigação de microquimerismo materno uma vez que um modelo experimental de LES desenvolvido em camundongos envolve a introdução de células linfóides parentais DBA/2 na prole (C57BL/6 x DBA/2) F1. Neste modelo, anticorpos antinúcleo IgG são produzidos em grandes quantidades e há o desenvolvimento de glomerulonefrite fatal por imunocomplexos ${ }^{(31,32)}$. Estudos demonstraram que células fetais causam erupções na pele conhecidas como erupções polimórficas da gestação ${ }^{(33)} \mathrm{e}$, também, que estas células estão implicadas no desenvolvimento de préeclampsia ${ }^{(34)}$. Uma vez que o LES apresenta forte predileção feminina, possui uma síndrome semelhante à pré-eclampsia e alguns pacientes lúpicos apresentam uma deterioração clínica durante a gestação ${ }^{(35,36)}$, é procedente a hipótese de que também no LES haja participação de transfusão fetomaternal. Em 2001, Johnson et al. ${ }^{(37)}$ realizaram estudo com o objetivo de determinar se o tráfego celular feto-materno poderia estar envolvido no processo patogênico do LES. A presença de células masculinas de origem fetal foi analisada por hibridização in situ com sondas fluorescentes específicas para os cromossomos X e Y em tecido afetado e não afetado, obtidos da autópsia de uma mulher (com dois filhos homens) que havia falecido em conseqüência de vasculite secundária ao LES. Células masculinas foram encontradas em todos os tipos de tecidos alterados examinados, mas não foram encontradas em tecidos histológicos normais; sugerindo, assim, que as células fetais possam estar diretamente associadas com a patogênese do LES. A presença de células masculinas era mais proeminente nos órgãos e tecidos envolvidos no processo patológico da doença. Esse mesmo grupo demonstrou que em material de autópsia de 11 mulheres (com histórias de gestações não conhecidas) que morreram de causas não relacionadas a doenças autoimunes nenhuma célula masculina foi encontrada nos múltiplos órgãos. Na paciente lúpica estudada, as células masculinas apareciam tanto isoladas como em grupos. De acordo com os autores esses últimos podem refletir o potencial de divisão inata das células fetais e/ou a indução de diferenciação através do recrutamento de células progenitoras para as áreas de tecido danificado. Não está claro se a presença dessas células está relacionada com a causa da doença, se é um efeito do progresso da doença ou se não está relacionado com a patologia do LES. Entretanto, esse estudo trouxe evidência para uma potencial relação entre a patologia do LES e o tráfego celular feto-materno. Este é um dos únicos trabalhos publicados em que foi estudada uma possível relação entre microquimerismo fetal e o desenvolvimento do LES; desta maneira, estudos adicionais são necessários para confirmar e delinear a participação das células fetais na patogênese do LES.

\section{MICROQUIMERISMO FETAL NA SÍNDROME DE SJÖGREN}

A síndrome de Sjögren é uma doença auto-imune caracterizada por infiltração linfocitária nas glândulas salivares e lacrimais ${ }^{(38)}$ e variável produção de vários auto-anticorpos ${ }^{(39)}$. Embora alguns estudos tenham demonstrado que o processo patológico da SSj pode estar associado a inúmeros fatores de origem viral, endócrina, neural e genética, o mecanismo responsável pelo desenvolvimento da doença continua desconhecido ${ }^{(5,40-42)}$. A SSj é mais freqüente em mulheres do que em homens, em uma proporção de $9: 1^{(43)}$. Muitos estudos descreveram o efeito de hormônios sexuais na predisposição feminina para doenças auto-imunes, incluindo $\mathrm{SSj}^{(5,44-47)}$. Andrógenos suprimem drasticamente a infiltração linfocitária em glândulas salivares e lacrimais de camundongos MRL/lpr femininos ${ }^{(46)}$; em contraste, exposição prénatal a estrógenos em camundongos normais induzem lesões nas glândulas salivares similares às lesões encontradas na SSj e aceleram a produção de auto-anticorpos ${ }^{(47)}$. Os hormônios sexuais podem ser um fator de risco para o desenvolvimento da SSj, mas a influência hormonal por si não parece ser suficiente para explicar a predisposição feminina na doença. Alguns sintomas da SSj são similares àqueles da GVHD, ambas as doenças apresentando atrofia progressiva e ressecamento da superfície mucosa. Amostras de biópsias de glândulas salivares ou lacrimais de pacientes com GVHD mostram infiltração linfocitária similar a que é encontrada na $\mathrm{SSj}^{(12,48)}$. Essas características indicam uma possível relação entre microquimerismo fetal e desenvolvimento da SSj. 
Em 2002, Kuroki et al. ${ }^{(49)}$ realizaram estudo para observar a presença de células fetais em amostras de glândula salivar e de fluido bronco-alveolar de 56 pacientes femininos com SSj, 36 com SSj primária e 20 com SSj secundária. Para tal utilizaram técnicas de nested PCR e FISH. Foi demonstrado que DNA masculino estava presente em 10/28 (36\%) das amostras de glândula salivar e em 2/9 (22\%) das amostras de fluido bronco-alveolar obtidas de pacientes com SSj (com pelo menos um filho); entretanto, DNA masculino não estava presente nas células mononucleares do sangue periférico. Não foram encontradas diferenças entre pacientes com SSj primária e secundária. A seqüência específica do cromossomo Y não foi encontrada nas amostras (glândula salivar labial e fluido bronco-alveolar) obtidas de controles.

Em um outro estudo com biópsias de glândulas salivares labiais de 16 mulheres com SSj primária e de 11 mulheres com ES, DNA masculino não foi encontrado em nenhuma biópsia de pacientes com $\mathrm{SSj}$, enquanto que $45 \%$ das pacientes com ES, independentemente de possuírem SSj secundária, apresentaram sequiências de DNA do cromossomo $Y^{(50)}$. Nesse estudo a sensibilidade da PCR era alta, uma vez que, em um experimento controle, DNA de três células masculinas, adicionado a DNA extraído de uma biópsia de glândula salivar menor de uma mulher sadia, foi sempre detectado. Como o microquimerismo fetal foi detectado nas glândulas salivares labiais de pacientes com $\mathrm{ES}$, mas não nas glândulas dos pacientes com $\mathrm{SSj}$, os autores concluíram que a patogênese das duas doenças difere e que a patogênese das lesões nos órgãos alvos da SSj primária não deve estar relacionada com a presença de microquimerismo fetal. Este estudo está de acordo com outro descrito anteriormente nesta revisão ${ }^{(17)}$, mostrando a possível presença de células masculinas em diferentes tecidos em mulheres com ES. Este estudo também concorda com o reportado por Toda et al. ${ }^{(51)}$, mostrando que microquimerismo fetal não foi detectado em sangue periférico ou em frações enriquecidas com CD34 de mulheres com SSj primária (analisados através de nested PCR e por uma combinação de PCR e hibridização in situ).

Em 2002, Endo et al. ${ }^{(52)}$ descreveram um estudo realizado por nested PCR com DNA de células mononucleares do sangue periférico de pacientes com SSj e ES para analisar a presença da seqüência específica do cromossomo Y. Não foi observada diferença significante na presença de microquimerismo entre os controles e pacientes com SSj ou ES. Entretanto, DNA masculino foi detectado em glândulas salivares em 11 de 20 mulheres com SSj, mas apenas em 1 de 8 controles. Células fetais foram claramente detectadas por hibridização in situ nas amostras de glândula salivar em 3 de 8 pacientes com SSj.

Observa-se que os estudos de microquimerismo em SSj apresentaram resultados contraditórios, talvez em razão da heterogeneidade na seleção de pacientes: SSj primária, SSj secundária, diferentes critérios de classificação de $\mathrm{SSj}$, presença de atividade da doença e diferentes regimes terapêuticos. Além disso, os estudos relatados detectam microquimerismo fetal testando seqüências distintas do cromossomo $\mathrm{Y}$, algumas das quais mostram reatividade cruzada com seqüências autossômicas ${ }^{(53)}$. Dessa forma, estudos adicionais utilizando pacientes com SSj são necessários para ajudar a elucidar a participação do microquimerismo fetal materno na patogênese da doença.

\section{MICROQUIMERISMO E PATOGÊNESE DAS DOENÇAS REUMÁTICAS AUTO-IMUNES}

Os mecanismos pelos quais o microquimerismo pode contribuir para a patogênese das doenças reumáticas autoimunes ainda não foram bem esclarecidos. Estudos investigaram quimerismo em receptores de órgãos transplantados e pacientes com GVHD. Foi proposta a hipótese de que a presença de microquimerismo celular do doador em receptores de órgãos facilita a aceitação do enxerto; isto explicaria a observação de que receptores de órgãos transplantados e que apresentam quimerismo não rejeitam o enxerto após terem suas drogas imunossupressoras suspensas ${ }^{(54)}$. Essa hipótese pode ter aplicação também para o microquimerismo observado durante a gravidez, já que na gravidez observa-se uma extraordinária tolerância ao enxerto fetal ${ }^{(55)}$. Entretanto, uma explicação para o microquimerismo persistir por muitos anos após o término da gestação ou ser a causa de uma doença auto-imune não está evidente ${ }^{(55)}$.

Os mecanismos que contribuem para a GVHD crônica foram resumidos ${ }^{(56)}$ :

- Células $T$ do doador não são eliminadas e não são toleradas pelo hospedeiro.

- Uma disfunção tímica causada por GVHD torna as células $\mathrm{T}$ em maturação auto-reativas.

- Predomínio de uma resposta mediada pelas citocinas produzidas pelas células Th2.

Pequenas quantidades de células não próprias poderiam ter um efeito desproporcional, como, por exemplo, uma interferência nas vias imuno-regulatórias do receptor (a mãe, no caso do microquimerismo) mediada por células não próprias ou por peptídeos não próprios. Acredita-se que a apresentação de peptídeos não próprios por células 
próprias participe na rejeição crônica ao enxerto (a qual apresenta algumas similaridades com ES) ${ }^{(55)}$. Alternativamente, células não próprias e células próprias poderiam interagir diretamente, por exemplo, um pequeno número de células fetais $\mathrm{CD} 8+$ poderia receber ajuda de células CD4+ próprias ${ }^{(57)}$, um processo provavelmente facilitado pela compatibilidade do HLA. Essas possibilidades não são mutuamente exclusivas e mais de um mecanismo poderia estar envolvido.

\section{AVALIAÇÃO CRÍTICA DOS ESTUDOS DE MICROQUIMERISMO}

Em pacientes com ES foi sugerido que células fetais CD3+ direcionariam uma reação GVHD nos tecidos maternos, porém a base para essa sugestão foi a identificação de células masculinas entre células CD3+ selecionadas em alguns poucos pacientes com ES onde não havia um grupo controle apropriado $^{(16)}$. Além do mais, o estudo original de mulheres saudáveis descreveu a presença de microquimerismo fetal em células $\mathrm{CD} 3{ }^{(4)}$ e, desde então, outros estudos têm confirmado que o microquimerismo é uma característica comum nas células CD3 de mulheres normais ${ }^{(58)}$. Por outro lado, analogias diretas das doenças auto-imunes com GVHD crônica requerem cautela, pois existem diferenças clínicas e quantitativas de quimerismo entre as doenças reumáticas auto-imunes e GVHD crônica ${ }^{(55)}$. Por exemplo, apesar das várias similaridades entre ES e GVHD crônica, existem numerosas diferenças em aspectos histopatológicos e clínicos, como por exemplo, o fenômeno de Raynaud e o envolvimento renal ${ }^{(59)}$. Outra diferença muito importante entre ES e GVHD crônica é a diferença quantitativa de quimerismo, o que também se aplica às outras doenças reumáticas estudadas. Na ES a razão entre as células nãopróprias e as células próprias pode ser estimada, através de alguns estudos, em até uma em um milhão de células brancas ou, no caso dos linfócitos, uma em 500.000. Em contraste, na GVHD crônica as células do doador substituem as células próprias circulantes ${ }^{(55)}$. Grandes quantidades de células quiméricas poderiam estar refugiadas nos tecidos afetados pela doença, entretanto, estudos de espécimes de pele em pacientes com ES sugerem que os níveis de microquimerismo também não são tão marcantes nesse tecido ${ }^{(16)}$.

Características técnicas também precisam ser consideradas na interpretação dos estudos de microquimerismo. Contaminação é uma grande preocupação em estudos de tecidos embebidos em parafina, uma vez que os banhos de parafina normalmente não são trocados entre as amostras. Estudos com espécimes de tecidos devem ser mais confiáveis quando são utilizadas técnicas como $\operatorname{FISH}^{(60)}$. Como a proporção de células fetais chega a uma em um milhão de células maternas, utiliza-se nested PCR para detectar a seqüência específica do cromossomo Y, uma técnica altamente sensível. Contaminação é um risco conhecido das técnicas básicas de PCR, sendo praticamente inevitável na nested PCR, onde são realizadas duas amplificações em seqüência, e o risco de contaminação entre elas é extremamente alto. Nossa própria experiência confirma a susceptibilidade à contaminação da técnica de nested PCR. Nosso grupo realizou alguns estudos com o objetivo de detectar pequenas quantidades de DNA masculino em DNA feminino. Para isso, foram preparadas diluições de sangue periférico masculino em sangue periférico de uma mulher nuligesta nas proporções de 1:102, 1:104 e 1:106 (simulando o microquimerismo fetal-materno) e, em seguida, foi extraído o DNA dessas amostras. Os experimentos foram realizados por nested PCR com as mesmas seqüências de primers utilizados em alguns dos estudos citados anteriormente como, por exemplo, por Artlett et al. ${ }^{(16)}$. Para evitar contaminação, cada etapa do experimento foi realizada com muita atenção e minucioso cuidado (preparação das amostras em capela de fluxo laminar com luz ultra-violeta e utilizando ambientes distintos para cada etapa da nested PCR; materiais estéreis, auto-clavados e expostos à radiação ultravioleta; ponteiras com filtro; troca de luvas entre a manipulação de cada amostra; centrifugação dos microtubos com produto de amplificação antes de abri-los; entre outras cautelas). Entretanto, os resultados mostraram um alto nível de contaminação nas amostras dos controles negativos (Figura 1). É interessante notar que a intensidade das bandas correspondentes ao produto amplificado dos controles negativos foi superior ao da diluição 1:106. A seguir, novas tentativas foram realizadas com o objetivo de evitar esta contaminação. Algumas características da reação foram alteradas, por exemplo, tempos de ciclagem menores foram utilizados para diminuir a sensibilidade da reação. Como resultado obteve-se um controle negativo sem amplificação, entretanto a diluição de 1:106 não pôde ser detectada e praticamente não se observa amplificação na diluição 1:104 (Figura 2). Resultados semelhantes foram encontrados quando realizada apenas a segunda etapa da PCR, em que conseguimos não detectar amplificação alguma no controle negativo, entretanto a técnica não foi sensível para detectar uma célula masculina em um milhão de células femininas (Figura 3). Esta é uma dificuldade do estudo de microquimerismo, a técnica precisa ser sensível o suficiente para detectar uma quantidade muito pequena de células, 
entretanto, os índices de contaminação tornam-se extremamente altos, colocando sob suspeita os resultados obtidos. Dessa maneira, os estudos com microquimerismo fetalmaterno devem ser analisados minuciosamente quanto às técnicas empregadas, os controles e amostras utilizados, aspectos clínicos e história gestacional dos pacientes, duração da doença, e, então, ser interpretados com muita cautela.

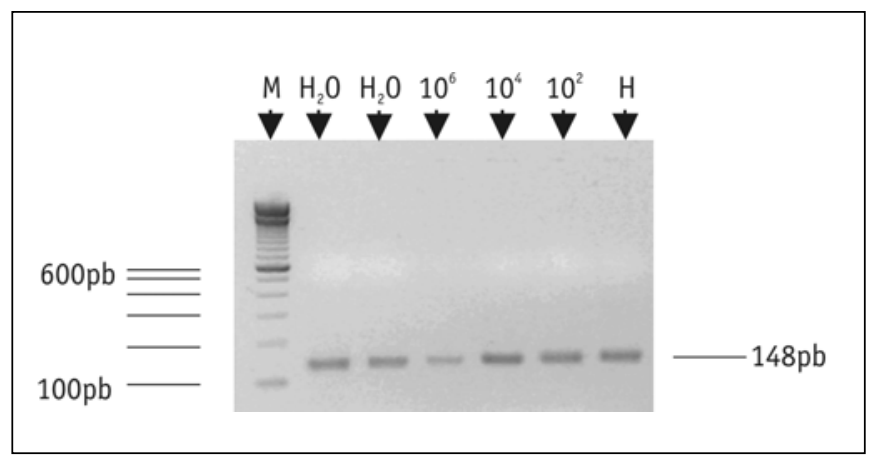

FIGURA 1 - Análise por eletroforese em gel de agarose de produtos da nested PCR utilizada para detecção de pequenas quantidades de DNA masculino em DNA feminino. 0 produto amplificado correspondente à seqüência específica do cromossomo Y é de $148 \mathrm{pb}$. M-marcador de peso molecular; $\mathrm{H}_{2} \mathrm{O}$ controle negativo sem DNA; $10^{6}, 10^{4}$ e $10^{2}$-diluições seriadas de DNA masculino em DNA de nuligesta nas proporções $1: 10^{6}, 1: 10^{4}$ e 1:10², respectivamente; $\mathrm{H}$-DNA extraído se sangue periférico masculino.

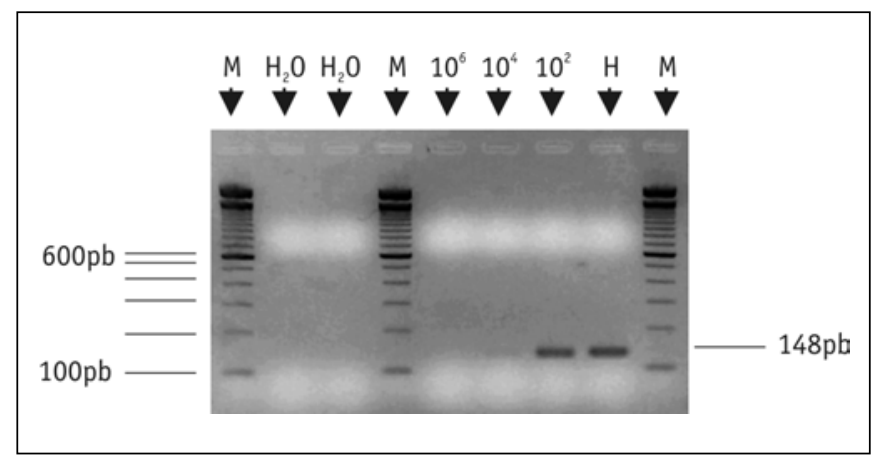

Figura 2 - Análise por eletroforese em gel de agarose de produtos da nested PCR utilizada para detecção de pequenas quantidades de DNA masculino em DNA feminino com diminuições nos tempos da ciclagem. 0 produto amplificado correspondente à seqüência específica do cromossomo $\mathrm{Y}$ é de $148 \mathrm{pb}$. M-marcador de peso molecular; $\mathrm{H}_{2} \mathrm{O}$-controle negativo sem DNA; $10^{6}, 10^{4}$ e $10^{2}$-diluições seriadas de DNA masculino em

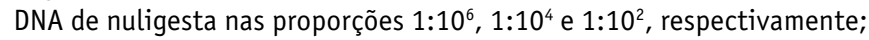
H-DNA extraído se sangue periférico masculino.

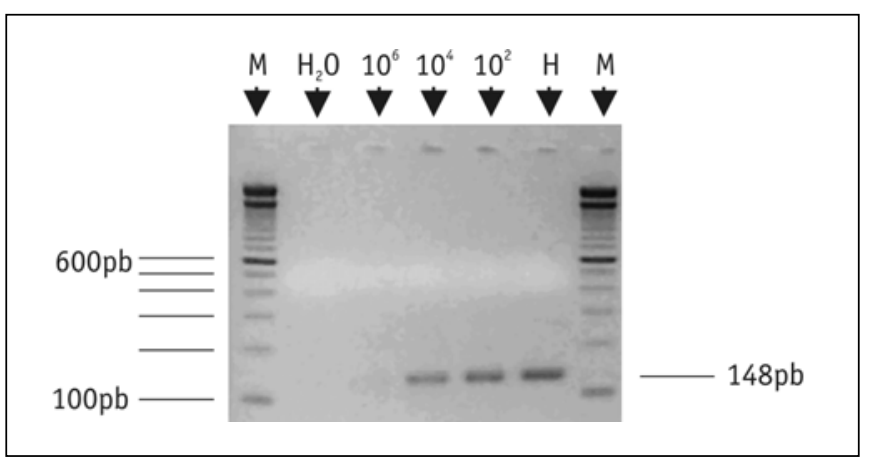

FIgURA 3 - Análise por eletroforese em gel de agarose de produtos da PCR realizada apenas com a segunda etapa da nested PCR para detecção de pequenas quantidades de DNA masculino em DNA feminino. 0 produto amplificado correspondente à seqüência específica do cromossomo $Y$ é de 148pb. M-marcador de peso molecular; $\mathrm{H}_{2} \mathrm{O}$-controle negativo sem DNA; $10^{6}, 10^{4}$ e $10^{2}$-diluições seriadas de DNA masculino em DNA de nuligesta

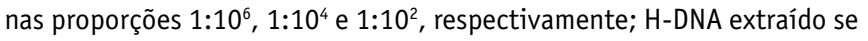
sangue periférico masculino.

\section{CONCLUSÃO}

Grande parte dos resultados dos estudos mencionados oferece suporte à hipótese de que o microquimerismo fetalmaterno esteja envolvido na patogênese de algumas doenças reumáticas auto-imunes, principalmente na ES. Entretanto, há considerável controvérsia na literatura, o que pode se dever à extrema sensibilidade da reação de nested PCR utilizada, que pode contribuir para resultados espúrios. Ainda que genuíno, o aumento do microquimerismo nos pacientes poderia ser secundário ao processo da doença e não necessariamente representar um fator causal da mesma. Desta forma, estudos adicionais são necessários para validação dos achados e para um preciso entendimento do mecanismo do microquimerismo fetal na patogênese dessas doenças. Como o microquimerismo é comum em mulheres sadias, são importantes estudos cuidadosamente planejados e seleção de populações controles apropriadas. Ainda que controverso, este é um tema de grande importância, pois, demonstrado que o microquimerismo contribui para a patogênese de algumas doenças auto-imunes, novas estratégias terapêuticas podem ser desenvolvidas para contornar este fator específico.

\section{AGRADECIMENTOS}

Este trabalho foi parcialmente subsidiado pelo Conselho Nacional de Desenvolvimento e Pesquisa (CNPq) e pelo Fundo de Auxílio e Pesquisa em Ensino em Reumatologia da Sociedade Brasileira de Reumatologia. 


\section{REFERÊNCIAS}

1. Bianchi DW: Prenatal diagnosis by analysis of fetal cells in maternal blood. J Pediatr 127: 847-56, 1995.

2. Thomas MR, Williamson R, Craft I, Yazdani N, Rodeck CH: Y chromosome sequence DNA amplified from peripheral blood of women in early pregnancy. Lancet 343: 413-4, 1994.

3. Lo YMD, Tein MSC, Lau TK et al: Quantitative analysis of fetal DNA in maternal plasma and serum: implications for noninvasive prenatal diagnosis. Am J Hum Genet 62: 768-75, 1998.

4. Bianchi DW, Zickwolf GK, Weil GJ, Sylvester S, DeMaria MA: Male fetal progenitor cells persist in maternal blood for as long as 27 years postpartum. Proc Natl Acad Sci U S A 93: 705-8, 1996.

5. Homo-Delarche F, Fitzpatrick F, Christeff N, Nunez EA, Bach JF, Dardenne M: Sex steroids, glucocorticoids, stress and autoimmunity. J Steroid Biochem Mol Biol 40: 619-37, 1991.

6. Nelson JL: Microchimerism and the pathogenesis of systemic sclerosis. Curr Opin Rheumatol 10: 564-71, 1998.

7. Sullivan K: Graft-versus-host disease. In Forman ST, Blume KG, Thomas ED: Bone Marrow Transplantation, Oxford, Blackwell Scientific, 1994. p. 339-62.

8. Lee TH, Paglieroni T, Holland PV, Busch MP: Frequent engraftment of donor stem cells in multiply transfused trauma patients. Blood 93: 3127-39, 1999.

9. De Moor G, De Bock G, Noens L, De Bic S: A new case of humam chimerism detected after pregnancy: 46, XY karyotype in the lymphocytes of a woman. Acta Clin Belg 43: 231-5, 1988.

10. Lo YMD, Lo ESF, Watson $\mathrm{N}$ et al: Two-way cell traffic between mother and fetus: biologic and clinical implications. Blood 88: 43905, 1996.

11. Hall JM, Lingenfelter P, Adams SL, Lasser D, Hansen JA, Bean MA: Detection of maternal cells in human umbilical cord blood using fluorescence in situ hybridization. Blood 86: 2829-32, 1995.

12. Lawley TJ, Peck GL, Moutsopoulos HM, Gratwohl AA, Deisseroth AB: Scleroderma, Sjögren-like syndrome, and chronic graft-versushost disease. Ann Intern Med 87: 707-9, 1977.

13. Lister L, Messner H, Keysonte E et al: Autoantibody analysis of patients with graft versus host disease. J Clin Lab Immunol 24: 1923, 1987.

14. Rouquette-Gally A, Boyeldieu D, Prost A, Gluckman E: Autoimmunity after allogeneic bone marrow transplantation. Transplantation 46: 238, 1988.

15. Nelson JL, Furst DE, Maloney S et al: Microchimerism and HLAcompatible relationships of pregnancy in scleroderma. Lancet 351: 559-62, 1998.

16. Artlett CM, Smith JB, Jimenez SA: Identification of fetal DNA and cells in skin lesions from women with systemic sclerosis. N Engl J Med 338: 1186-91, 1998.

17. Johnson KL, Nelson JL, Furst DE et al: Fetal cell microchimerism in tissue from multiple sites in women with systemic sclerosis. Arthritis Rheum 44: 1848-54, 2001.

18. White B: Pathogenesis: immune aspects. In Clements PJ, Furst DE: Systemic sclerosis, Baltimore, Williams and Wilkins, 1996. p. 229-50.

19. Galperin C, Gershwin ME: Systemic sclerosis (scleroderma). In Rose NE. Mackay IR: The autoimmune diseases, 3rd ed., San Diego, Academic Press, 1998. p. 317-42.
20. Mosmann TR, Coffman RL: TH1 and TH2 cells: different patterns of lymphokine secretion lead to different functional properties. Annu Rev Immunol 7: 145-73, 1989.

21. Romagnani S: Lymphokine production by human $\mathrm{T}$ cells in disease states. Annu Rev Immunol 12: 227-57, 1994.

22. Mavalia C, Scaletti C, Romagnani P et al: Type 2 helper T-cell predominance and high CD30 expression in systemic sclerosis. Am J Pathol 151: 1751-8, 1997.

23. Hasegawa M, Fujimoto M, Kikuchi K, Takehara K: Elevated serum levels of interleukin 4 (IL-4), IL-10, and IL-13 in patients with systemic sclerosis. J Rheumatol 24: 328-32, 1997.

24. Atamas SP, Yurovsky VV, Wigley FM et al: Production of type 2 cytokines by CD8+ lung cells is associated with greater decline in pulmonary function in patients with systemic sclerosis. Arthritis Rheum 42: 1168-78, 1999.

25. Ong C, Wong C, Roberts CR, Teh HS, Jirik FR: Anti-IL-4 treatment prevents dermal collagen deposition in the tight-skin mouse model of scleroderma. Eur J Immunol 28: 2619-29, 1998.

26. De Wit D, van Mechelen M, Zanin C et al. Preferential activation of Th2 cells in chronic graft-versus-host reaction. J Immunol 150: 361-6, 1993.

27. Sakurai J, Ohata J, Saito K et al: Blockade of CTLA-4 signals inhibits Th2-mediated murine chronic graft-versus-host disease by an enhanced expansion of regulatory CD8+ T cells. J Immunol 164: 664-9, 2000.

28. Scaletti C, Vultaggio A, Bonifacio S et al: Th2-oriented profile of male offspring $\mathrm{T}$ cells present in women with systemic sclerosis and reactive with maternal major histocompatibility complex antigens. Arthritis Rheum 46: 445-50, 2002

29. Nelson JL: Maternal-fetal immunology and autoimmune disease. Is some autoimmune disease auto-alloimmune or allo-autoimmune? Arthritis Rheum 39: 191-4, 1996.

30. McMilin KD, Johnson RL: HLA homozygosity and the risk of related-donor transfusion-associated graft-versus-host disease. Transfus Med Rev 7: 37-41, 1993.

31. Gleichman E, Van Elven H, Van der Veen JP: A systemic lupus erythematosus (SLE)-like disease in mice induced by abnormal T-B cell cooperation. Eur J Immunol 12: 152-5, 1982.

32. Portanova JP, Ebling FM, Hammond WS, Hahn BH, Kotzin BL: Allogeneic MHC antigen requirements for lupus-like autoantibody production and nephritis in murine graft-vs-host disease. J Immunol 141: 3370-6, 1988.

33. Aractingi S, Berkane N, Bertheau $\mathrm{P}$ et al: Fetal DNA in skin of polymorphic eruptions of pregnancy. Lancet 352: 1898-901, 1998.

34. Holzgreve W, Ghezzi E, DiNaro E, Ganshirt D, Maymon E, Hahn S: Fetomaternal cell traffic is disturbed in preeclampsia. Obstet Gynecol 91: 669-72, 1998.

35. Petri M: Pregnancy in SLE. Baillieres Clin Rheumatol 12: 449-76, 1998.

36. Meng C, Lockshin M: Pregnancy in lupus. Curr Opin Rheumatol 11: 348-51, 1999.

37. Johnson KL, McAlindon TE, Mulcahy E, Bianchi DW: Microchimerism in a female patient with systemic lupus erythematosus. Arthritis Rheum 44:2107-11, 2001

38. Anaya J, Talal N: Sjögren's syndrome and connective tissue diseases associated with other immunologic disorders. In Koopman WJ: Arthritis and allied conditions, Baltimore, Williams \& Wilkins, 1997. p. $1561-80$. 
39. Tan EM: Antinuclear antibodies: diagnostic markers for autoimmune diseases and probes for cell biology. Adv Immunol 44: 93-151, 1989.

40. Homo-Delarche F, Fitzpatrick F, Christeff N, Nunez EA, Bach JF, Dardenne M: Sex steroids, glucocorticoids, stress and autoimmunity. J Steroid Biochem Mol Biol 40: 619-37, 1991.

41. Fox R, Saito I: Sjögren's syndrome: immunologic and neuroendocrine mechanisms. Adv Exp Med Biol 350: 609-21, 1994.

42. Sullivan D: Possible mechanisms involved in reduced tear secretion in Sjögren's syndrome. In Homma M, Sugai S, Tojo T, Miyasaka N, Akizuki M: Sjögren's syndrome. State of art, Amsterdam, Kugler Press, 1994. p. 13-9.

43. Strickland RW, Tesar J, Berne B, Hobbs B, Lewis D, Welton R: The frequency of sicca syndrome in an elderly female population. $\mathrm{J}$ Rheumatol 14: 766-71, 1985.

44. Schuurs AH, Verheul HA: Effects of gender and sex steroids on the immune response. J Steroid Biochem 35: 157-72, 1990.

45. Carlsten H, Nilsson N, Jonsson R, Backman K, Holmdahl R, Tarkowski A: Estrogen accelerates immune complex glomerulonephritis but ameliorates $\mathrm{T}$ cell-mediated vasculitis and sialadenitis in autoimmune MRL lpr/lpr mice. Cell Immunol 144: 190-202, 1992.

46. Ariga H, Edwards J, Sullivan DA: Androgen control of autoimmune expression in lacrimal glands of MRL/Mp-lpr/lpr mice. Clin Immunol Immunopathol 53: 499-508, 1989.

47. Ahmed SA, Aufdemorte TB, Chen JR, Montoya AI, Olove D, Talal $\mathrm{N}$ : Estrogen induces the development of autoantibodies and promotes salivary gland lymphoid infiltrates in normal mice. J Autoimmun 2: 543-52, 1989.

48. Ogawa Y, Okamoto S, Wakui M et al: Dry eye after hematopoietic stem cell transplantation. Br J Ophthalmol 83: 1125-30, 1999.

49. Kuroki M, Okayama A, Sasaki T et al: Detection of maternal-fetal microchimerism in the inflammatory lesions of patients with Sjögren's syndrome. Ann Rheum Dis 61: 1041-6, 2002.
50. Aractingi S, Sibilia J, Meignin V et al: Presence of microchimerism in labial salivary glands in systemic sclerosis but not in Sjögren's syndrome. Arthritis Rheum 46: 1039-43, 2002.

51. Toda I, Kuwana M, Tsubota K, Kawakami Y: Lack of evidence for an increased microchimerism in the circulation of patients with Sjögren's syndrome. Ann Rheum Dis 60: 248-53, 2001.

52. Endo Y, Negishi I, Ishikawa O: Possible contribution of microchimerism to the pathogenesis of Sjögren's syndrome. Rheumatology 41: 490-5, 2002.

53. Giacomelli R, Matucci-Cerinic M, Bombardieri S: Microchimerism in Sjögren`s syndrome. Ann Rheum Dis 61: 1039-40, 2002.

54. Starzl TE, Demetris AJ, Murase N, Trucco M, Thomson AW, Rao AS: The lost chord: microchimerism and allograft survival. Immunol Today 17: 577-84, 1996.

55. Nelson JL: Non-host cells in the pathogenesis of autoimmune disease: a new paradigm? Ann Rheum Dis 58: 518-20, 1999.

56. Hakim FT, Mackall CL: The immune system: effector and target of graft-versus-host disease. In Ferrara JL, Deeg HJ, Burakof ST: Graft-vs-host disease, 2nd ed., New York, Marcel Deker, 1997. p. $274-89$.

57. Suzuki K, Narita T, Yui R, Asakura H, Fujiwara M: Mechanism of the induction of autoimmune disease by graft-versus-host reaction. Role of CD8+ cells in the development of hepatic and ductal lesions induced by CD4+ cells in MHC class I plus II different host. Lab Invest 70: 609-19, 1994.

58. Evans PC, Lambert N, Maloney S, Furst DE, Moore JM, Nelson JL: Long-term fetal microchimerism in peripheral blood mononuclear cell subsets in healthy women and women with scleroderma. Blood 93: 2033-7, 1999.

59. Aractingi S, Dausset J, Carosella ED: Chimerism in scleroderma. [Letter]. Lancet 351: 1996, 1998.

60. Nelson JL: Pregnancy and microchimerism in autoimmune disease: protector or insurgent? Arthritis Rheum 46: 291-7, 2002. 